\title{
AC 2011-1952: IMPACT OF DIFFERENT CURRICULAR APPROACHES TO ETHICS EDUCATION ON ETHICAL REASONING ABILITY
}

\author{
Robert M Bielby, University of Michigan
}

Robert Bielby is a doctoral student in the Center for the Study of Higher and Postsecondary Education focusing in higher education policy and quantitative methodology.

\section{Trevor Scott Harding, California Polytechnic State University}

Dr. Trevor S. Harding is Chair and Professor of Materials Engineering at California Polytechnic State UniversitySan Luis Obispo where he teaches courses in biomaterials, solidification metallurgy, tribology and life cycle design. Dr. Harding has published numerous manuscripts in the area of ethical development of engineering undergraduates through application of psycho-social models of moral expertise. He also conducts research in student motivation, service learning, and project-based learning. His technical research is focused on degradation of biomedical materials in vitro. He currently serves as Associate Editor of the online journal Advances in Engineering Education, is Chair of the ASEE Materials Division, and was ERM Vice-Chair for the 2010 ASEE Annual Conference. He recently received the 2008 President's Service Learning Award for innovations in the use of service learning at Cal Poly. In 2004 he was named a Templeton Research Fellow by the Center for Academic Integrity, Duke University. Dr. Harding received both the 1999 Apprentice Faculty Grant and 2000 New Faculty Fellow Award for his contributions to engineering education.

\section{Donald D. Carpenter, Lawrence Technological University}

Dr. Donald Carpenter is an Associate Professor of Civil Engineering and the Director of Assessment at Lawrence Technological University. Prior to being Director of Assessment, Dr. Carpenter was the Founding Director for the Center of Teaching \& Learning at Lawrence Tech where he was responsible for conducting faculty development programs. In addition, Dr. Carpenter actively conducts educational and pedagogical research on teamwork, leadership, and ethical development and is Kern Fellow for Entrepreneurial Education.

\section{Cynthia J. Finelli, University of Michigan}

Dr. Cynthia Finelli, Ph.D., is Director of the Center for Research and Learning in Engineering and research associate professor in the College of Engineering at the University of Michigan. In addition, she actively pursues research in engineering education and assists other faculty in their scholarly projects. She is past Chair of the Educational Research and Methods Division of ASEE and guest co-editor for a special issue of the International Journal of Engineering Education on applications of engineering education research.

\section{Janel Sutkus, Carnegie Mellon University \\ Brian A. Burt, University of Michigan \\ Eunjong Ra, University of Michigan \\ Matthew Holsapple, University of Michigan}

Matthew Holsapple is a doctoral candidate in Center for the Study of Higher and Postsecondary Education at the University of Michigan, and he has spent the last three years researching engineering ethics education. His research interests include moral development and character education in college students, professional ethics education, and research design and quasi-experimental methods in college student outcomes research. 


\section{Impact of Different Curricular Approaches to Ethics Education on Ethical Reasoning Ability}

As engineers enter the workplace, they must not only be aware of the existing ethical standards required to become a professional engineer, but they must also be prepared to reason through ethical problems and act appropriately in their everyday work. However, recent research has shown that the traditional curricular approaches used to develop these skills in engineering undergraduates - notably case studies and emphasis on ethical codes - do not have as great an impact on students' ability to address ethical issues as expected. ${ }^{1}$ It is therefore the intention of this study to evaluate a number of different curricular approaches to ethics education (e.g. roleplaying activities, games, or films) that could be used to prepare students for ethical issues and to assess their impacts on students' ethical reasoning ability. Additionally, we test the differential impact of curricular approaches, regardless of the type, related to the depth of cognitive processing required during the experience.

While previous work has evaluated different curricular approaches to engineering education, this study contributes to the discourse by conducting quantitative analysis on data collected from a variety of engineering programs across the United States. This approach will allow for a more general understanding of both the current state of ethics education in engineering and based on the relationships between curricular experiences and outcomes related to ethical development.

\section{Previous Research}

Research evaluating the current state of ethics education in engineering has primarily succeeded in describing extant curricular approaches and suggestions for alterations that would be expected to benefit students. ${ }^{23456}$ Lynch provides a snapshot of the state of engineering curricula related to ethics in the late 1990s, describing that many engineering programs were beginning to both include stand-alone ethics courses along with the inclusion of ethics considerations in technical coursework. ${ }^{5}$ The motivations behind the development of these new curricular experiences are further discussed by Rabins in part to respond to accreditation criteria from the Accreditation Board for Engineering and Technology (ABET) that includes ethics. ${ }^{67}$

More recent research in the field has come to adopt a critical lens in evaluating different approaches the ethics education. Herkert discusses the overemphasis of microethics frames (i.e. individual professional ethics in engineering) in recently developed online ethics modules, while ignoring many issues of macroethics associated with social responsibility. ${ }^{3}$ Kline similarly professes the need for engineering ethics to move away from "disaster" case studies in the education of students. ${ }^{4}$ Instead, the use of historical and sociological perspectives is encouraged to motivate the treatment of ethics as an everyday component of the engineering profession.

Drake et al. comparatively evaluate the use of ethics modules within extant engineering courses and a full-semester ethics course at a single institution. ${ }^{2}$ No significant improvements in student outcomes were related to either curricular choice when compared to a control group. 
Newberry confronts the potentially superficial treatment of ethical issues in engineering education. ${ }^{8}$ Here it is argued that the treatment of ethics education as an academic exercise, as opposed to a professional and even emotional endeavor, reduces student engagement with the material.

In addition to mode of presentation, the level at which students are required to process the information presented to them through their curricular experiences is expected to heavily impact their level of development. One lens through which this level of processing can be understood is that of Bloom's taxonomy. ${ }^{9}$ The taxonomy hierarchically classifies thought processes into six levels depending on complexity (See Figure 1). The levels begin at simple memorization of facts or knowledge and progress through individuals taking stances based upon the information with which they have been presented and justifying those stances with evidence. It is our expectation that students who are required to behave in accordance with the highest levels of Bloom's taxonomy will obtain higher levels of developmental outcomes due to more in depth processing of the engineering ethics curriculum.

While these perspectives provide some theoretical evidence of what may be needed to improve ethics education, they are not associated with solid empirical proof of the impacts the current or suggested curricular

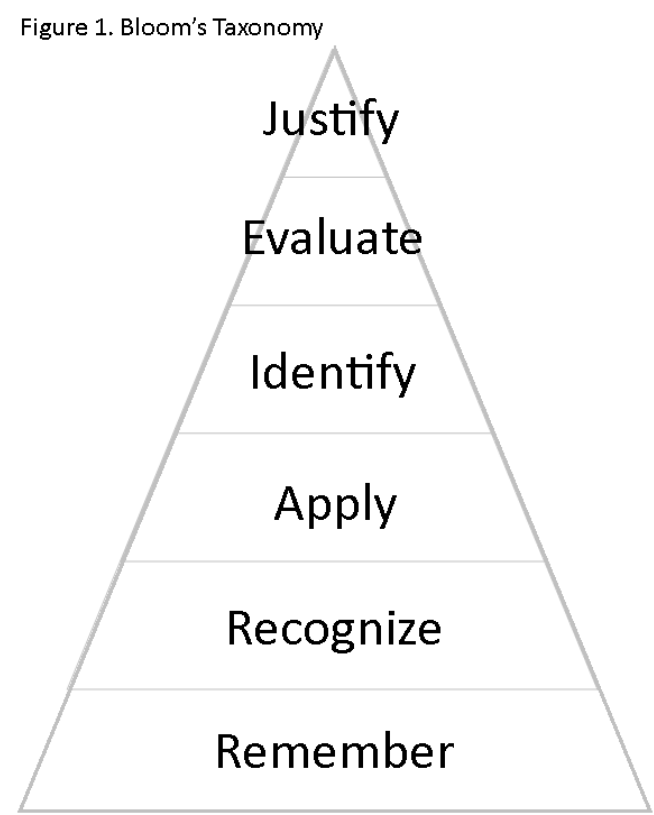
experiences. Our analysis is intended to expand upon this literature by using a theoretical model of student development to inform the construction of specific research questions to be tested with empirical analysis.

\section{Conceptual Model}

We have developed a conceptual model, based upon Astin's Input-Environment-Outcome (IEO) model and a modification of that model developed by Terenzini and Reason. ${ }^{10}{ }^{11}$ Each model shows the relationship between student characteristics (input), the college experience (environment), and students' developmental results (outcome). Terenzini and Reason and our model (see Figure 2), expand the understanding of the different aspects of the college environment that both directly and indirectly impact student development. In our research we focus on the application of this model to ethical development. We define ethical development as consisting of three components: ethical knowledge, ethical reasoning, and ethical behavior, each of which is an independent construct with potentially varying relationships to different curricular approaches to ethics education curricula and to one another. For the purposes of this analysis, we will be specifically focusing on the direct relationship between students' curricular experiences and their level of ethical reasoning.

To test these relationships in relation to issues posed in previously conducted research, we will attempt to answer the following research questions: 
-Do different curricular approaches to ethics education have differential impacts on undergraduate students' ethical reasoning ability?

-How does the impact of these approaches differ for students across academic class-years?

-Regardless of approach type, what impact does the depth of cognitive processing involved in experiences have on students' ethical reasoning ability?

Figure 2. Conceptual model of a student's ethical development during college

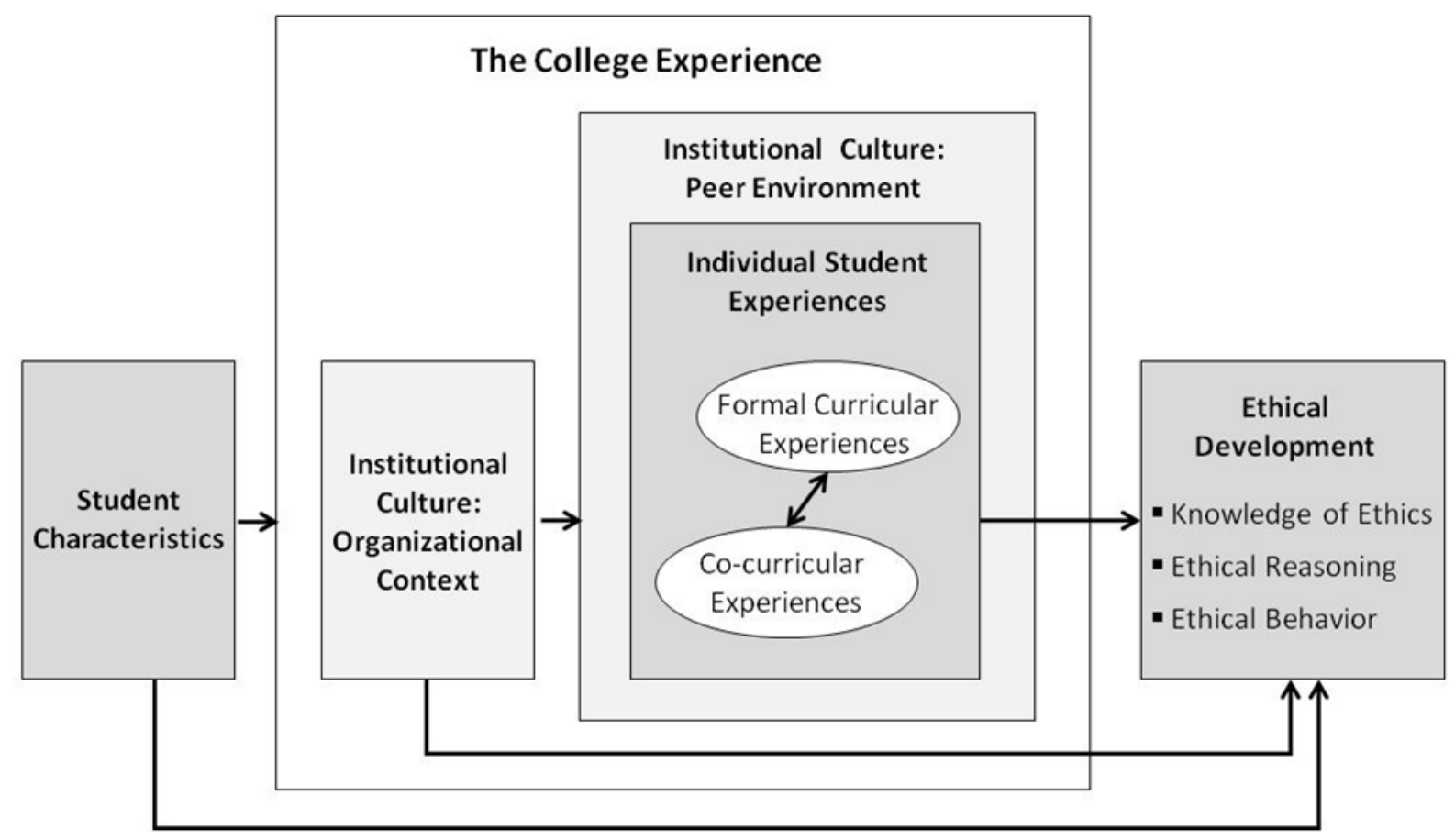

\section{Method}

We used a dataset that was collected as part of a survey of ethical development among engineering students conducted at 18 higher education institutions across the U.S. ${ }^{12}$ The institutions in the sample were selected to provide a wide range of institution size, program concentration, and geographic region. Amongst other things, the survey included items measuring students' exposure to curricular and co-curricular ethics education experiences, measures of ethical knowledge, ethical reasoning, and both pro-social and antisocial ethical behavior.

\section{Dependent Variable}

The dependent variable of interest for this analysis is students' scores on the Defining Issues Test-2 (DIT-2) N2 scale of moral reasoning. ${ }^{13}$ The DIT-2 requires respondents to reason through a series of five moral dilemmas (e.g. a father considers stealing food to feed his starving 
family). They are then asked to rate a series of 12 statements related to each dilemma (1-5) in terms of importance. The $\mathrm{N} 2$ is a scale constructed from survey responses and each respondent's $\mathrm{N} 2$ provides a continuous measure which estimates the degree to which respondents prioritize moral criteria and devalue adhering to social conventions in their moral judgment. Higher N2 Scores correspond to more highly developed moral reasoning skills and more cognitively complex reasoning. The DIT-2 N2 scale has been thoroughly tested for both validity and reliability as a measure. ${ }^{14} \mathrm{We}$ apply scores on this scale as a measure of ethical reasoning, our outcome of primary interest.

\section{Independent Variables}

The main independent variables of interest to the analysis are indicator variables signifying students' participation in a number of curricular and co-curricular experiences related to ethics within and outside of their engineering program. In order to focus the analysis, we focused specifically on the curricular experiences that were encountered within the engineering program. The variables are coded 1 if a student reported participating in an experience and 0 otherwise. Each experience is situated within one of three contexts: Introductory Course, Advanced Course, or Capstone Course. Additionally, each pertains to one of nine modes of presentation. Contexts and modes of presentation therefore combine into 27 curricular experiences in which students could indicate participating. ${ }^{1}$ A variable was also generated to represent the total number of engineering curricular experiences related to ethics experienced by each student by simply summing up each of the individual experience indicator variables.

A second independent variable of interest is the depth of processing required in curricular experiences. This item was measured using a scale related to Bloom's taxonomy of intellectual objectives. ${ }^{9}$ Regarding the curricular experience they were most likely to reference when confronted with a future ethical dilemma, respondents were asked to report each level of cognitive depth at which they were asked to process the experience. The responses ranged from "Remember facts presented through this activity" to "Justify the decision you would make if faced with the same ethical dilemma." We then used the highest level reported by each respondent as the overall level of complexity related to the experience. The resulting variable is coded from 0 "none of the above" to 6 "justify."

All models also included a set of control variables to account for differences across race (coded using indicator variables for underrepresented minorities and Asians, excluding whites as the comparison group), gender (an indicator variable for males compared to females), and past academic performance, measured using high school grade point average (coded on a standard 4.00 scale).

\section{Models}

The above variables are used in a multivariate regression framework to test the relationships that exist between the differing types of curricular interventions and ethical reasoning ability. Models using specific curricular experiences as independent variables were

\footnotetext{
${ }^{1}$ Contexts and modes of presentation are specifically listed in Table 2 of the results section as the column and row labels respectively.
} 
conducted independently of one another due to relatively high levels of correlation between the experience indicators. Having high levels of correlation between independent variables in a multiple regression framework is referred to as multicollinearity. The presence of

multicollinearity in a model results in inflated standard errors and unstable estimates. While this limits our ability to control for the presence of other curricular experiences in each model, it allows for more consistent and reliable estimates of the relationships between each curricular experience and ethical reasoning ability.

\section{Results}

\section{Number and Type of Experiences}

The total number of curricular experiences to which a student had been exposed was found to have a modest, negative statistically significant effect on ethical reasoning ability when the data were aggregated across class years (see Table 1). When the data were disaggregated, we found that the negative relationship was heavily driven by students in the early stages of their education. This finding contradicted the expectation that higher levels of exposure to curricular experiences related to ethics would be related to higher levels of ethical reasoning ability. It is not the number of experiences to which students are exposed, but instead the quality of the experiences that has the greatest impact, as can be seen in the section below.

Table 1. Influence of Total Number of Curricular Experiences on Ethical Reasoning Ability

\begin{tabular}{|c|c|c|c|c|c|c|c|c|c|c|}
\hline & All Students & & Freshmen & & Sophomores & & Juniors & & Seniors & \\
\hline & $\begin{array}{c}\text { Unstandardized } \\
\text { Coefficient }\end{array}$ & & $\begin{array}{c}\text { Unstandardized } \\
\text { Coefficient }\end{array}$ & & $\begin{array}{c}\text { Unstandardized } \\
\text { Coefficient }\end{array}$ & & $\begin{array}{c}\text { Unstandardized } \\
\text { Coefficient }\end{array}$ & & $\begin{array}{c}\text { Unstandardized } \\
\text { Coefficient }\end{array}$ & \\
\hline Total Number of Experiences & -0.191 & $* *$ & -0.571 & $* * *$ & -0.704 & $* * *$ & -0.397 & $7 *$ & 0.056 & \\
\hline Underrepresented Minority & -4.053 & $* * *$ & -3.971 & $* * *$ & -6.584 & $* * *$ & -0.869 & & -2.876 & \\
\hline Asian & -1.323 & $*$ & -1.869 & & -0.957 & & -3.618 & $3 *$ & 0.452 & \\
\hline Gender (Male) & -4.617 & $* * *$ & -5.034 & $* * *$ & -3.441 & $* * *$ & -5.930 & $* * *$ & -3.795 & $* * *$ \\
\hline High School GPA & 1.063 & $* * *$ & 1.222 & $* * *$ & 0.471 & & 1.168 & $* * *$ & 1.298 & $* * *$ \\
\hline Constant & 32.613 & $* * *$ & 31.944 & $* * *$ & 37.535 & $* * *$ & 35.386 & $* * *$ & 28.653 & $* * *$ \\
\hline$N$ & 3341 & & 1070 & & 820 & & 747 & & 697 & \\
\hline Adjusted R-squared & 0.043 & & 0.055 & & 0.041 & & 0.067 & & 0.0339 & \\
\hline
\end{tabular}

Large variation was found in the impact of specific curricular experiences when the data were aggregated across class years (see Table 2). With the exception of presentation by a professor, there was a consistent negative trend of all specific curricular experiences when presented in an introductory class. 


\begin{tabular}{|c|c|c|c|c|}
\hline & Introductor & ory & Advanced & Capstone \\
\hline Presentation by a Professor & 0.332 & & $1.649 * *$ & $2.028 * *$ \\
\hline Presentation by an Experienced Engineer & $-1.616 *$ & $* * *$ & 0.757 & $2.736 * * *$ \\
\hline Presentation by a Guest Speaker & $-2.561 *$ & $* * *$ & 0.502 & 1.761 \\
\hline Group Discussion with Classmates & -0.221 & & 0.227 & $2.715 * *$ \\
\hline Movie or Film & $-2.057 *$ & $* * *$ & 0.230 & -1.383 \\
\hline Skit or Other Persormance & $-2.918 *$ & $* * *$ & -4.739 & -4.739 \\
\hline In-Class Game & $-3.475 *$ & $* * *$ & -0.512 & 0.112 \\
\hline Roleplay of Ethical Decision Making & -0.351 & & 1.563 & 0.040 \\
\hline $\begin{array}{l}\text { Online Simulations, Tutorials, } \\
\text { or Other Online Modules }\end{array}$ & $-3.403 *$ & $* * *$ & -1.185 & -3.268 \\
\hline \multicolumn{5}{|c|}{$\begin{array}{l}\text { Note: Each of the above coefficients was produced from a model regressing the indicator for the specific } \\
\text { curricular experience and controls for race, gender, and academic ability. }\end{array}$} \\
\hline \multicolumn{5}{|l|}{${ }^{*} \mathrm{p}<0.1,{ }^{* *} \mathrm{p}<0.05, * * * \mathrm{p}<0.01$} \\
\hline
\end{tabular}

Positive and statistically significant relationships to ethical reasoning ability were found for a presentation by a professor in an advanced or capstone course, a presentation by an experienced engineer in a capstone course, and group discussions with classmates in a capstone course. When these models were disaggregated by class year, it was found that each of the significant relationships was driven by senior class respondents (See Table 3). While some statistical significance was lost due to decreases in sample size, the magnitude of each positive relationship is maintained in each case among seniors. Magnitude and direction of effect were found to be much less consistent among junior respondents.

Table 3. Influence of Specific Curricular Experiences on Ethical Reasoning Ability (By Class Year)

\begin{tabular}{|c|c|c|c|c|}
\hline & \multicolumn{2}{|c|}{ Advanced } & \multicolumn{2}{|c|}{ Capstone } \\
\hline & Juniors & Seniors & Juniors & Seniors \\
\hline Presentation by a Professor & -0.271 & $1.953551 *$ & 0.783 & 1.558356 \\
\hline Presentation by an Experienced Engineer & - & $-\quad$ & -0.893 & $2.444846 *$ \\
\hline Group Discussion with Classmates & - & - & 1.297 & $2.235946 *$ \\
\hline \multicolumn{5}{|c|}{$\begin{array}{l}\text { Note: Each of the above coefficients was produced from a model regressing the indicator for the specific curricular } \\
\text { experience and controls for race, gender, and academic ability. }\end{array}$} \\
\hline \multicolumn{4}{|c|}{${ }^{*} p<0.1, * * p<0.05, * * * p<0.01$} & \\
\hline
\end{tabular}

\section{Bloom's Taxonomy}

The highest level of Bloom's taxonomy that students reported being "required in their experience expected to most likely impact them in the future" was found to have a positive and statistically significant relationship with their level of ethical reasoning (See Table 4). The relationship was found to be such that an increase of one level of Bloom taxonomy was associated with approximately a .56 point increase in their $\mathrm{N} 2$ score. When we consider a transition from the lowest to highest level of the taxonomy, this would result in about a 3.4 point shift in N2 score. Such a shift is comparable in magnitude to the difference between men and women ( -4.6 points) and the difference between whites and underrepresented minorities ( -4.1 points). This effect was found to have the same direction and a similar level of impact when the data were disaggregated by class year, though some statistical significance was lost due to the reduction in sample size in each class. As anticipated, the depth of cognitive processing required by students' curricular experiences is associated with increases in ethical reasoning ability. 
Table 4. Influence of Cognitive Depth of Curricular Experiences on Ethical Reasoning Ability

\begin{tabular}{|c|c|c|c|c|c|c|c|c|c|c|}
\hline & \multicolumn{2}{|l|}{ All Students } & \multicolumn{2}{|l|}{ Freshmen } & \multicolumn{2}{|l|}{ Sophomores } & \multicolumn{2}{|l|}{ Juniors } & \multicolumn{2}{|l|}{ Seniors } \\
\hline & $\begin{array}{c}\text { Unstandardized } \\
\text { Coefficient }\end{array}$ & & $\begin{array}{c}\text { Unstandardized } \\
\text { Coefficient }\end{array}$ & & $\begin{array}{c}\text { Unstandardized } \\
\text { Coefficient }\end{array}$ & & $\begin{array}{c}\text { Unstandardized } \\
\text { Coefficient }\end{array}$ & & $\begin{array}{c}\text { Unstandardized } \\
\text { Coefficient }\end{array}$ & \\
\hline Blooms Level & 0.557 & $* * *$ & 0.327 & & $0.498 *$ & $* *$ & 0.956 & $* * *$ & 0.389 & \\
\hline Underrepresented Minority & -3.664 & $* * *$ & -3.471 & $* * *$ & -6.458 * & $* * *$ & -0.784 & & -2.583 & \\
\hline Asian & -1.273 & $*$ & -1.818 & & -0.827 & & -3.478 & $* *$ & 0.288 & \\
\hline Gender (Male) & -4.602 & $* * *$ & -4.657 & $* * *$ & $-3.877 *$ & $* * *$ & -6.743 & $* * *$ & -3.757 & $* * *$ \\
\hline High School GPA & 0.991 & $* * *$ & 1.203 & $* * *$ & 0.356 & & 1.101 & $* * *$ & 1.228 & $* * *$ \\
\hline Constant & 29.830 & $* * *$ & 28.062 & $* * *$ & $34.821 *$ & $* * *$ & 31.371 & $* * *$ & 27.480 & $* * *$ \\
\hline$N$ & 3163 & & 993 & & 777 & & 706 & & 680 & \\
\hline Adjusted R-squared & 0.045 & & 0.044 & & 0.0355 & & 0.0791 & & 0.0325 & \\
\hline
\end{tabular}

\section{Demographics}

Gender was found to have a consistent negative relationship with N2 score across our analyses. Males tended to score about 4 points lower on the scale than females. This finding is in the same direction and of comparable magnitude findings of previous research. ${ }^{15}$ Students from underrepresented minority and Asian backgrounds were also found to have consistently lower N2 scores, though the relationship for Asian students was not always statistically significant.

\section{Discussion}

The finding that the total number of ethics curricular experiences is not positively related to ethical reasoning ability suggests that mere exposure to ethics will not necessarily improve student outcomes. In fact, it appears that, particularly students in lower class levels, actually respond negatively to being overexposed to ethics curricula. This may suggest that students early in their engineering education are not yet properly versed in the field to truly absorb and apply the information presented in ethics discussions.

It appears that it is not the quantity of exposure that is most important, but instead the quality of the individual experiences. This is reinforced by the finding that the depth of cognitive processing required by the student's most important experience was strongly and positively related to ethical reasoning. Additionally, while it was found that the experiences that had the strongest individual impacts on students' ethical reasoning ability occurred later in the academic experience, it was also found that experiences with higher levels of cognitive depth had significant impacts on lower class levels.

\section{Limitations}

One of the major limitations of this analysis is the need to aggregate data across institutions in order to obtain sufficient statistical power. While there are commonalities across institutions in their presentation of similar curricular experiences, it is likely that there is also a high level of inter-institutional variation. Future analyses should look to more specifically analyze particular curricular selections and their impact on students' ethical reasoning. 
In order to conduct such research as is suggested above, data collection would have to transition from the cross-sectional nature of this study to a longitudinal design. While crosssectional data allows for correlational analysis of the relationships between students' previous experiences and their current levels of ethical reasoning, longitudinal analysis allows for insight into the potential causal relationships between curricular experiences and student outcomes.

Additionally, future data collection should look to acquire more information from primary sources instead of relying on respondents' self-reports in all cases. Such data could be acquired from students' transcripts, both high school and college, and from school curricula and even syllabi. One specific variable of importance to our analysis which would greatly benefit from a more objective form of measurement would be the level of cognitive processing required by curricular experiences. Such data would first provide more reliable information that is much less likely to be impacted by social desirability biases and would also provide a much clearer image of the current standing of engineering ethics education in American institutions of higher education.

Future analyses should also look to test for subgroup differences, both by gender and race, for the relationships found here. While direct effect relationships were found between both race and gender and ethical reasoning ability, it may be expected that curricular experiences may differentially impact students of different races and genders. Due to length limitations, this could not be perused within this analysis.

\section{Implications}

The findings of this analysis suggest that the most important factor in developing a student's ethical reasoning ability is exposing students to curricular experiences that require them to think deeply about ethical issues at the highest levels of Bloom's Taxonomy. While longitudinal data are not currently available to track students across their full college experiences, we found that experiences with higher levels of cognitive depth had similar impacts on students in each class year. We therefore expect that the way to have the strongest impact on students' ethical reasoning development is to concentrate on providing curricular experiences requiring a consistently high level of cognitive processing across all class years.

\section{Bibliography}

1. Bucciarelli, L.L. (2008). Ethics and engineering education. European Journal of Engineering Education, 33 (2), 141-149.

2. Drake, M.J., Griffin, P.M., Kirkman, R., and Swann, J.L. (2005). Engineering ethical curricula: Assessment and comparison of two approaches. Journal of Engineering Education, 94 (2), 223-231.

3. Herkert, J.R. (2005). Ways of thinking about and teaching ethical problem solving: Microethics and macroethics in engineering. Science and Engineering Ethics, 11 (3), 373385. 
4. Kline, R.R. (2002). Using history and sociology to teach engineering ethics. Technology and Society Magizine, IEEE, 20 (4), 13-20.

5. Lynch, W.T. (1998). Teaching engineering ethics in the United States. Technology and Society Magazine, IEEE, 16 (4), 27-36.

6. Rabins, M.J. (1998). Teaching engineering ethics to undergraduates: Why? What? How? Science and Engineering Ethics, 4 (3), 291-302.

7. ABET. (2011). Criteria for accrediting engineering programs: Efective for evaluations during the 2010-2011 accreditation cycle. ABET, Inc: Baltimore, MD.

8. Newberry, B. (2004). The dilemma of ethics in engineering education. Science and Engineering Ethics, 10 (2), 343-351.

9. Bloom, B. S. (1956). Taxonomy of educational objectives, handbook I: The cognitive domain. New York: David McKay Co Inc.

10. Astin, A. (1993). What matters in college? Four Critical Years revisited. San Francisco: Jossey-Bass.

11. Terenzini, P. T., \& Reason, R. D. (2005,). Parsing the first year of college: Rethinking the effects of college on students. Paper presented at the Annual Conference of the Association for the Study of Higher Education: Philadelphia, PA.

12. $\mathrm{E}^{3}$. (2011). www.engin.umich.edu/research/e3/research/seed.html.

13. Rest, J.R., Narvaez, D., \& Thoma, S.J. (1999). DIT2: Devising and testing a revised instrument of moral judgment. Journal of Educational Psychology, 91 (4), 644-659.

14. Rest, J.R., Thoma, S. J., Narvaez, D., \& Bebeau, M. J. (1997). Alchemy and beyond: Indexing the Defining Issues Test. Journal of Educational Psychology, 89 (3), 498-50.

15. Maeda, Y., Thoma, S.J., Bebeau, M.J. (2009). Understanding the relationship between moral judgment development and individual characteristics: The role of educational contexts. Journal of Educational Psychology, 101 (1), 233-247. 